\title{
Ur hotzeko murgilketa kirol errekuperazioa metodo gisa
}

(Cold-water immersion as a recovery method in sport)

Iratxe Duñabeitia*, Jon Torres-Unda, Javier Gil, Susana M. ${ }^{a}$ Gil, Jon Irazusta, Iraia Bidaurrazaga-Letona

Fisiologia saila, Medikuntza eta Erizaintza Fakultatea (UPV/EHU)

LABURPENA: Kirolariengan entrenamenduen edota txapelketen osteko errekuperazio desegokiak estres fisiologiko handia, gainkarga sintomak eta nekea eragin ditzake, errendimendua gutxituz. Hori dela eta, eguneroko entrenamenduak ziurtatzeko eta lesionatzeko arriskuak murrizteko, fisioterapian hainbat agente fisiko erabiltzen dira errekuperazio metodo gisa, hala nola, hidroterapia. Hidroterapian hainbat modalitate erabili daitezke ur hotzeko murgilketak, besteak beste. Kirol munduan ur hotzeko murgilketa errekuperazio metodo ezagunenetarikoa eta erabilienetakoa da eta denbora labur batez beheko gorputzadarrak ur hotzean murgiltzean oinarritzen da. Ikerketa asko egon arren, bere efektuak ez daude argi eta kontraesanak daude. Lan honetan, lehenengo, hidroterapiaren printzipioen laburpen bat egiten da eta, ondoren, ur hotzeko murgilketaren kontraindikazioak, erabilpenak eta efektuak azaltzen dira, betiere kirol errekuperazioaren ikuspegitik.

HITZ GAKOAK: agente fisikoa, hidroterapia, ur hotzeko murgilketa, errekuperazioa.

ABSTRACT: After training or a competition bad recovery can produce high physiological stress, overload and fatigue in athletes, which can reduce physical performance. Thus, physiotherapy applies different types of physical agents like hydrotherapy as a recovery method in sport to ensure every day training and reduce injury risk. There are many hydrotherapy applications, but cold-water immersion is one of the most used and recognized recovery method in sport. In cold-water immersion, lower limbs are immersed in cold water during a short period. In this sense, there are many researches but cold-water immersion effects are not clear and there are controversial results. In this article, we described hydrotherapy theorems and then, we detailed cold-water immersion contraindications, uses and effects as a recovery method in sport.

KEYWORDS: physical agents, hydrotherapy, cold-water immersion, recovery.

\footnotetext{
* Harremanetan jartzeko / Corresponding author: Iratxe Duñabeitia, Fisiologia saila, Medikuntza eta Erizaintza Fakultatea (UPV/EHU). Sarriena kalea z/g, 48940, Leioa, Bizkaia Euskal Herria. - iratxe.dunabeitia@ehu.eus - https://orcid.org/00000002-8683-289X.

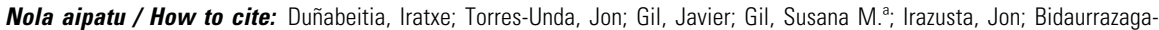
Letona, Iraia (2020). «Ur hotzeko murgilketa kirol errekuperazioa metodo gisa»; Ekaia, 37, 2020, 291-304. (https://doi.org/10.1387/ekaia.20848).

Jasoa: 14 maiatza, 2019; Onartua: 07 urria, 2019.

ISSN 0214-9001 - eISSN 2444-3255 / (c) 2020 UPV/EHU
}

(c) (i) (2) Obra hau Creative Commons Atribución 4.0 Internacional-en lizentziapean dago 


\section{SARRERA}

Intentsitate altuko entrenamendu errepikakorren edota txapelketen ostean, gainkargak sortzen dira eta batez ere, mina eta nekea dira agertzen diren sintomarik adierazgarrienak [1]. Nekea, giharrek indarra edo potentzia sortzeko duten gaitasunaren gutxipenean oinarritzen da eta errendimenduan eragina du, hots, errendimendu txikiagoa izatea eragiten du [2]. Besteak beste, nekeak funtzio neuromuskularra, indarra sortzeko gaitasuna [3] eta oreka [4] kaltetzen ditu. Horrela, neke horrek aldaketa fisiologiko eta biomekaniko negatiboak eragin ditzake kirolariengan [5, 6].

Lesioak ekiditeko eta disfuntzioak edota desgaitasunak leheneratzeko, fisioterapiak, besteak beste, agente fisikoak erabiltzen ditu [7]. Agente hitzak «egin» esan nahi du eta, aldiz, fisikoa «naturatik datorrena» esan nahi du, alegia, naturatik datorren baliabidea [8]. Horrela, agente fisikoak naturan aurkitzen diren baliabideak izan daitezke: naturalak edo artifizialak (gizakiak sortzen dituenak). Bestalde, agente fisikoek sor ditzaketen eraginak lehen mailakoak (termikoak, mekanikoak, kimikoak eta elektromagnetikoak) edo bigarren mailakoak (lehen mailako efektuen ondorioz sortutako efektuak) izan daitezke [9].

Agente fisiko hauek prebentzio moduan ere erabiltzen dira eta, askotan, berreskuratze metodo gisa. Horrela, kirol arloan asko erabili izan dira agente fisikoak entrenamenduen edo txapelketen ostean [1,10]. Agente fisiko ezagunenetariko eta erabilienetako horien artean hidroterapia aurkitzen da.

\section{HIDROTERAPIA}

Hidroterapia hitza grekotik dator; hydor «ura» esan nahi du eta therapeia «terapia», hots, uraren bidez egiten den terapiari egiten dio erreferentzia [11].

Urak energia mekanikoaren zein termikoaren bitartez efektu terapeutikoak dituela ikusi da. Hortaz, uraren printzipioak honako hauek dira [11-13]:

\section{Printzipio mekanikoak}

Faktore hidrostatikoak, hidrodinamikoak eta hidrozinetikoak daude.

\section{Faktore hidrostatikoa}

Printzipioaren oinarria flotazioa da, alegia, bultzada edo Arkimedes-en printzipioa. Printzipio honen arabera, urak goranzko indar bertikala eragi- 
ten dio uretan sartuta dagoen edozein gorputzi. Bultzadazko indar hau hustutako uraren pisuaren balio berekoa da. Presio hidrostatikoa likidoaren dentsitatearekin eta murgiltze sakontasunarekin proportzionalki zuzena da. Horrela, gorputza uretan murgiltzean hautematen den sentsazioa, gorputzaren pisua txikiagoa dela da eta, ondorioz, gorputza uretan errazago mugitu daiteke.

Gorputzaren eta bultzadaren arteko ezberdintasunari itxurazko pisua deritzo, eta arnasketaren (espirazio behartuan gorputza urperatu egiten da eta inspirazio maximoan flotatu egiten $\mathrm{du}$ ), sexuaren, adinaren, gaitasun bitalaren eta gorputz dentsitatearen arabera aldatzen da. Adibidez, uraren maila subjektu baten trokanterretaraino heltzen denean, gorputzak \% 66ko itxurazko pisua izango du.

Pascalen legearen arabera, uraren presio hidrostatikoak konpresio faktorea sortzen du, hau da, likidoaren edozein puntutan transmititutako presioa likidoaren puntu guztietara transmititzen da. Presio hau, gorputzaren pisu zehatzaren eta uraren mailaren altuera absolutuaren menpe dago. Alde batetik, gorputza bertikal jarrita dagoenean barrunbe torazikoaren perimetroaren gutxitzea eragiten du $(1 \mathrm{~cm}$-tik $3.5 \mathrm{~cm}$-ra) eta, bestetik, barrunbe abdominalarena $(2.5 \mathrm{~cm}$-tik $6.5 \mathrm{~cm}$-ra). Horrela, oxigeno kontsumoaren gutxitzearen ondorioz, aldaketa metabolikoak eragiten ditu eta, honek guztiak, gihar erlaxazioa eta tonua gutxitzea bultzatzen ditu.

\section{Faktore hidrodinamikoa}

Faktore hau definitzeko, erresistentzia hidrodinamikoa kontutan hartu behar da. Gorputz batek mugimendu bat egiten duenean, 900 aldiz handiagoa den erresistentzia jasango du uretan murgilduta dagoenean airean mugimendu berbera egiten duenean baino. Natura bidezko baliabidearen izaera ere kontuan hartu behar da, izan ere, funtsezko lau faktoreren araberakoa izango baita: kohesio intermolekularraren indarra, gainazaleko tentsioa, likidoaren biskositatea eta dentsitatea.

Faktore hidrodinamiko honek adierazten du gorputz bat uretan murgiltzen denean eta ura barruan dagoen gorputza mugitzen denean, presio desberdintasunak jasango dituela eta turbulentziak sortuko direla mugimendua oztopatuz.

\section{Faktore hidrozinetikoak}

Urak gorputzean egiten duen presioan oinarritzen da, adibidez, txorrotak eta dutxak. Honako aldagai hauen arabera, faktore zinetiko honek efektu desberdinak sor ditzake: uraren presio atmosferikoa, txorrotaren inklinazio angelua edota erresistentzia maila urpean egiten bada. 
Iratxe Duñabeitia, Jon Torres-Unda, Javier Gil, Susana M. ${ }^{a}$ Gil, Jon Irazusta, Iraia Bidaurrazaga-Letona

\section{Printzipio termikoak}

Aplikazioak hotzak edo beroak izan daitezke, baina ur hotzaren aplikazioetan jarriko dugu arreta.

\section{Hotzaren erabileraren eragina}

Gorputzeko tenperatura normaletik zenbat eta gehiago aldendu (34$36^{\circ} \mathrm{C}$ batzuentzat eta beste batzuentzat $31-33^{\circ} \mathrm{C}$ ), hainbat eta handiagoa da estimulu termikoa (termogenesi prozesua edo beroa sortzeko prozesua). Gorputz-adarrak tenperatura aldaketei egokitzeko gaitasun gutxiago dute.

Zenbat eta azalera handiagoan aplikatu, orduan eta efektu termiko handiagoa du.

Subjektuaren ezaugarriak eta sentsibilitate termikoak ere eragina dute.

Uraren tenperatura, gorputzeko tenperatura normaletik behera aldentzen denean, hauxe gertatzen da:

- Tenperaturaren jaitsierak ehunen basokonstrikzioa sortzen du eta batzuetan dardara termikoak sor ditzake. Pertsona argalek denbora gutxiago behar dute efektuak nabaritzeko eta efektua nabarmenagoa da. Gehiegizko denborak orbain prozesua atzeratu egiten du eta kontraindikatuta dago gaitz baskularrak dituzten subjektue$\tan$.

- Analgesia eta gihar erlaxazioa sortzen du. Nerbio-bukaera askeen kitzikakortasuna gutxitu, min atalasea handitu eta gihar espasmoak gutxitu egiten ditu. Dardara termikoak kontrakoa eragiten du.

- Zirkulazio sistema eta nerbio sistema indartzen ditu.

\section{Faktore kimikoak}

Ur mineromedizinal edo kimikoren bat atxikita daramaten urak dira.

Hidroterapiaren printzipioak oinarri izanik, hidroterapiaren barnean hainbat modalitate ezagutzen dira: ur hotzeko murgilketa $\left(<15^{\circ} \mathrm{C}\right)$, ur tenperatura naturalean murgiltzea $\left(15^{\circ} \mathrm{C}-36^{\circ} \mathrm{C}\right)$, ur beroko murgilketa $\left(>36^{\circ} \mathrm{C}\right)$ eta kontraste metodoa, non ur hotzaren eta ur beroaren murgilketak aldizkatzen diren [14]. Dena den, kirolari askok ur hotzeko murgilketak egiten dituzte, antzinako metodo ekonomikoa eta egiten erraza baita. 


\section{UR HOTZEKO MURGILKETA (UHM)}

UHM terapia gorputza $\leq 15^{\circ} \mathrm{C}$-ko ur hotzean murgiltzean oinarritzen da [15-17]. Orokorrean, beheko gorputz-adarrak ur hotzean murgiltzen dira [18], nahiz eta hainbat ikerketatan gorputz osoko murgilketak ere egin diren (burua eta lepoa izan ezik). Ikerketa hauetan uraren tenperaturak $-10^{\circ} \mathrm{C},-60^{\circ} \mathrm{C}$ edota $-110^{\circ} \mathrm{C}$ bitartekoak dira $[19,20]$.

UHMren sailkapen bat dago tenperatura eta murgilketa denboraren arabera [18]:

- Tenperaturari dagokionez: $5-10^{\circ} \mathrm{C}-\mathrm{ko}$ tenperaturan egiten diren urmurgilketak «oso hotzak» dira eta $11-15^{\circ} \mathrm{C}$-ko tenperaturan egiten direnak «neurrizkoak» dira.

- Murgilketa denborari dagokionez: 5-10 minutuko murgilketak «murgilketa laburrak» dira, 11-15 minutukoak «neurrizko murgilketak» eta 15-20 minutukoak «murgilketa luzeak» dira.

Oro har, ur hotzeko murgilketei buruzko azken berrikuspen sistematikoen eta metaanalisien arabera, min muskularra arintzeko emaitzarik onenak $11-15^{\circ} \mathrm{C}$-ko tenperaturan eta $11-15$ minutuko murgilketetan ikusi izan dira [18].

UHMren erabilpenak eta efektuak azaldu baino lehen, ezinbestekoa da dituen kontraindikazioak aipatzea, oso metodo ezagun eta erabilia izan arren, edonork ezin baitu erabili.

\subsection{UHMren kontraindikazioak}

Uraren tenperaturaren arabera, ur hotzetan murgildutako denboraren eta murgilketa motaren arabera, odol-fluxua, ekintza metabolikoa eta nerbioen abiaduraren eroapena aldatzen da [18]. Hori dela eta, zein gorputzatal murgiltzen den eta gorputz-atal hori noraino murgiltzen den, arriskutsua izan daiteke ur hotzetan murgiltzea $[17,18]$. Besteak beste, UHMk hiperaireztapena sor dezake eta, honek, arterien karbono dioxidoaren $\left(\mathrm{CO}_{2}\right)$ murrizketa eragin odolaren azidosia sortuz eta konortea galduz. Horrenbestez, honako segida hau sor dezake: takikardiak, gorputzeko adarren basokonstrikzioa, konbultsioak, bentrikuluaren ektopia eta bihotz-maiztasunaren gelditzea [17]. Horregatik, UHMk hainbat kontraindikazio ditu (1. taula) $[13,17]$ : 
Iratxe Duñabeitia, Jon Torres-Unda, Javier Gil, Susana M. ${ }^{a}$ Gil, Jon Irazusta, Iraia Bidaurrazaga-Letona

1. taula. Ur hotzeko murgilketaren (UHM) kontraindikazioak

\begin{tabular}{c}
\hline UHMren kontraindikazioak \\
\hline- Gaixotasun kroniko desorekatuak. \\
- Gutxiegitasun kardiakoa. \\
- Birikietako gutxiegitasuna. \\
- Gaizki kontrolatutako hipertentsio arteriala. \\
- Zainetako gutxiegitasun larria. \\
- Gaixotasun erreumatikoak. \\
- Kolitisak. \\
- Zistitisak. \\
- Beherakoa. \\
- Iskemia. \\
- Raynaud sindromea. \\
- Larruazaleko anestesia edo hipoestesia. \\
- Krioglobulinemia. \\
- Hotza jasateko ezintasuna.
\end{tabular}

\subsection{UHMren erabilpenak}

Azken urteetan, ariketa fisikoa egin ostean sortzen den hantura eta giharren mina gutxitzeko eta errekuperazio denbora murrizteko erabili da UHM terapia [17, 18, 21-24]. Horrela, hainbat egoera desberdinetan ikertu izan dira UHM terapiak sortzen dituen efektuak; intentsitate altuko entrenamendu interbalikoen ostean [25, 26], korrika test-maximalen ostean [27], aldapa behera korrika egin ostean [28], futbol-partiden ostean $[29,30]$, futbol entrenamenduen ostean [31], saskibaloi-partiden ostean [32], jauzi desberdinak burututakoan [33-35], uzkurdura eszentrikoak egin ostean [36, 37], bizikleta test-maximal baten ostean [38], edota bizikletan ibiltzea eta korrika egitea konbinatzen zituen protokolo baten ostean [39].

\subsection{UHMren efektuak}

UHM aplikazioak presio hidrostatikoak odol-fluxua espazio intrazelularretik espazio interstizialera eta intrabaskularrera mugitzea errazten du. Ondorioz, metabolitoen kanporatzea arintzen da [17, 40]. Ariketa fi- 
sikoak, zelulen iragazkortasuna handitzen du eta espazio intrazelularrean CK (Creatine Kinase) areagotzen du, biak, nekea edota giharren minaren adierazgarri direlarik. Horrela, ikusi da UHMk gutxitu dezakeela ariketa fisikoaren ondorioz handitzen den odoleko CK kantitatea [22, 29] Honen adibide gisa, korrikalari talde batek 30 minutuz zinta batean korrika egin zuten (abiadura maximoaren \% 70ra) eta, ondoren, 15 segundoko 10 serie burutu zituzten abiadura maximoan. Korrika proba bukatu eta jarraian, 15 minutuko $10^{\circ} \mathrm{C}$-ko UHM aplikazioa jaso zuten hanka batean; beste hanka kontrola izan zen. Horrela, UHM aplikazioa jaso zuten hankan kirolarien perfusio mikrobaskularra eta giharretako ekintza metabolikoa gutxitu ziren [41]. Informazio hau garrantzitsua izan daiteke oxigenoaren eskuragarritasunak giharretako unitate motorea doitzen baitu [42] eta, horrek, kirol errendimenduan eragina izan dezakeelako. Hala ere, efektu hauek ez daude batere argi eta literaturan kontraesanak aurki daitezke. Honen harira, beste ikerketa batzuetan, odoleko CK kantitatean ez da aldaketarik gertatzen $[33,35]$.

Uraren tenperatura baxua denean, bihotz-maiztasuna gutxitu egiten da; era berean, bihotzaren erantzuna gutxitzen denez eta noradrenalina kontzentrazioa handitzen denez, sistema sinpatikoa pizten da. Gainera, arterien odol-presioa eta gorputz-adarren erresistentzia baskularra handitzen da. Horrela, odola gorputz-adarretara bideratzen da gorputzak tenperatura manten dezan [16, 43-46]. Literaturan ikusi da, gihar-tenperaturaren gutxitzeak eta presio hidrostatikoak edemaren, minaren eta metabolitoen pilaketa gutxitu dezakeela $[15,17]$. Bederen, gihar-tenperaturaren gutxitzeak azaleko errezeptoreak estimulatuko ditu, zuntz sinpatiko adrenergikoak kitzikatuko ditu, arteriolen eta zainen konstrikzioa eragingo du eta, horrek, hantura prozesua gutxituko du $[17,47]$. Bestalde, UHM terapiak sortzen duen azetilkolina produkzioaren murrizketa dela eta, nerbio-kinaden abiaduraren eroapena eta giharren espasmoak gutxitu ditzake, neuronen transmisioa gutxituz $[17,48]$. Era berean, zenbait ikerketak iradokitzen dute terapia honek, $\mathrm{Ca}^{2+}$-aren eta $\mathrm{Na}^{2+}$-aren arteko hartu-emanean eragina izan dezakeela [48]. Horrela, akzio-erreakzio potentziala [49], uzkurketa abiadura eta indarra egiteko gaitasuna [50] moteldu daitezke eta min pertzepzioa eta nekea gutxitu ere bai $[26,51]$. Hala ere, kontutan hartu behar da giharraren tenperatura gradu bateko beherakada bakoitzeko, \% 4-6ko uzkurtzeko indar dinamikoa galtzen dela [19].

Tenperaturari dagokionez, hainbat efektu sortzen dituela ikusi da. Zenbait autorek min sentsazioa $15^{\circ} \mathrm{C}$-tan hasten dela ikusi dute $[48,52]$. Bestalde, min muskularra arintzeko emaitzarik onenak $11-15^{\circ} \mathrm{C}$-ko tenperaturan eta 11-15 minutuko murgilketetan ikusi izan dira [18]. Hala ere, ikerketa batean lagina hiru taldetan banatu zuten; kontrol taldea, 10 minutuko $8^{\circ} \mathrm{C}$-ko ur-murgilketa jaso zuen taldea eta 10 minutuko $22^{\circ} \mathrm{C}$-ko urmurgilketa jaso zuen taldea. 10 minutuko $8^{\circ} \mathrm{C}$-ko ur-murgilketa jaso zuten 
Iratxe Duñabeitia, Jon Torres-Unda, Javier Gil, Susana M. ${ }^{a}$ Gil, Jon Irazusta, Iraia Bidaurrazaga-Letona

parte-hartzaileen giharren tenperaturaren murrizketa handiagoa izan arren, odol-fluxuaren murrizketa antzekoa izan zen bai $8^{\circ} \mathrm{C}$-tan eta baita $22^{\circ} \mathrm{C}$-tan ere [53].

Kontutan izan beharreko beste irizpide bat da ea UHM zein ariketa fisikoren ostean aplikatzen den. Izan ere, Hohenaueren [54] arabera, efektu analgesikoa handiagoa da UHM intentsitate altuko ariketa fisikoaren ostean (24-48 ordu) aplikatzen denean ariketa eszentrikoaren ostean aplikatzen denean baino.

Askotan, UHM terapia beste errekuperazio metodo batzuekin konparatzen da. Horrela, berrikuspen eta metaanalisi baten arabera, UHM aplikazioaren errekuperazioa metodo pasiboa baino hobea da [54]. Hain zuzen ere, min muskularrean (96 ordu arte) eta neke pertzepzioan (24 ordu arte) hobekuntza adierazgarriak eragiten dituela ikusi izan da. Neke pertzepzioaren hobekuntza beste ikerketa batzuetan ere ikusi da [31, 55]. Bestalde, beste berrikuspen sistematiko eta metaanalisi batzuen arabera, UHMk ariketa fisikoaren osteko min muskularra gutxitu dezake [18, 22].

Alabaina, beste ikerketa batean, 30 gizonezkori intentsitate altuko entrenamendu interbalikoa egin ostean $(4 \times 30 \mathrm{~s}$ esprint $) 15$ minutuko errekuperazio aplikazioak egin zitzaizkien; ur hotzeko murgilketa $\left(10.30^{\circ} \mathrm{C} \pm 0.20^{\circ} \mathrm{C}\right)$, ur-murgilketa termoneutral plazeboa $\left(34.70^{\circ} \mathrm{C} \pm 0.10^{\circ} \mathrm{C}\right)$ eta ur-murgilketa termoneutral kontrola $\left(34.70^{\circ} \mathrm{C} \pm 0.10^{\circ} \mathrm{C}\right)$. Horrela, UHM jaso zuen taldeak plazebo eta kontrol taldeen emaitza antzekoak lortu zituen indarrean eta min muskularrean. Gainera, 48 ordura ur-murgilketa termoneutraleko plazeboa jaso zuen taldeak, ur-murgilketa termoneutraleko kontrola jaso zuenak baino indar errekuperazio handiagoa izan zuen eta, are gehiago, UHM bezain eraginkorra izan zen [21].

Hori dela eta, ur hotzeko murgilketen eraginkortasuna ez dago argi [56] eta azken ikerketek UHMk errendimenduan efektu negatiboak izan ditzakeela adierazi dute $[24,57,58]$.

Alde batetik, maratoi baten ostean korrikalari talde batek UHM jaso zuen, beste talde batek gorputz osoko UHM eta hirugarren talde batek plazebo tratamendua. Maratoiaren ostean, UHM jaso zuen taldeak ez zuen plazeboa jaso zuen taldeak baino emaitza hoberik lortu gihar funtzioen errekuperazioan eta hautematen den estres mailan [59]. Beste ikerketa batean, boleibol talde bateko jokalariek entrenamenduen ostean UHM jaso zuten 5 egunetan zehar. UHMk egunero sortutako egoera hormonala eta edema gutxitu arren, errendimenduan, min muskularrean, hantura markatzailetan eta ROS bitartekari seinalean sortutako efektuak mugatuak izan ziren [60]. Aitzitik, errekuperazio aktiboarekin konparatzen bada, erresistentziazko ariketa fisikoa egin ostean UHMk ez zuen errekuperazio aktiboak baino emaitza hoberik erakutsi hantura erantzunean edo giharraren estres zelularrean [61]. 
Bestetik, UHM era erregularrean jasotzen denean, ikusi da epe luzera entrenamenduen eraginez sortzen den gihar masa eta indarraren handitzea murrizten direla. Hain zuzen ere, indarra 12 astez bi aldiz entrenatzen zuten kirolariek UHM aplikazioak jasotzen zutenean, ikusi zen tratamenduak satelite zelulen ekintza inhibitu edo atzeratu egiten zuela eta p70S6K kinasaren aktibazioa bertan behera uzten zuela [24]. Era berean, Fröhlichen [57] ikerketa emaitza horiekin bat dator, alegia, UHM aplikazioak negatiboki eragin dezakeela epe luzeko indar entrenamenduan.

Bukatzeko, badirudi gorputzeko gantz kantitatearen arabera UHMk efektu desberdinak izan ditzakela. Izan ere, Stephensen [62] ikerketan, UHM jaso ostean gantz kantitate txikiagoa zuten gizonezkoek gantz gehiago zutenek baino gorputz tenperatura txikiagoa eta tenperatura pertzepzio baxuagoa izan zuten. Bestalde, UHM aplikazioak gantz gehiago zuten gizonezkoetan bakarrik lortu zuen errekuperazioan eragina izatea.

\section{ONDORIOAK}

Lan honen arabera, ur-hotzeko murgilketa lagungarria izan daiteke kirolariaren errekuperazio prozesuan entrenamendu edota txapelketa baten ostean. Izan ere, pertzepzioan hobekuntzak izan dira eta min muskularra eta neke muskularra arintzeko eraginkorra da. Dena den, ikerketa asko egon arren, beraren efektuak ez daude argi eta kontraesanak daude, ur hotzeko murgilketak epe luzeko indar entrenamenduan kalteak sortzen baititu. Hori dela eta, ikerketa gehiago egin beharko lirateke. Era berean, lan honetan ikusi den moduan, ur hotzeko murgilketa aplikazioak oso erabiliak izan arren, ezin dira pertsona edota kirolari guztietan era berdinean aplikatu. Hain zuzen ere, ur hotzeko murgilketa terapia bat denez, pertsona edota kirol bakoitzerako diseinu metodologiko pertsonalizatua izan beharko luke.

\section{BIBLIOGRAFIA}

[1] NUNES, G. S., BENDER, P. U., DE MENEZES, F. S., YAMASHITAFUJI, I., VARGAS, V. Z. eta WAGECK, B. 2016. «Massage therapy decreases pain and perceived fatigue after long-distance ironman triathlon: A randomised trial». Journal of Physiotherapy, 62(2), 83-87.

[2] KOMI, P. V. 2000. «Stretch-shortening cycle: A powerful model to study normal and fatigued muscle». Journal of Biomechanics, 33(10), 1197-1206.

[3] OKSA, J., RINTAMÄKI, H., TAKATALO, K., MÄKINEN, T., LUSA, S., LINDHOLM, H. eta RISSANEN, S. 2012. «Firefighters muscular recovery after a heavy work bout in the heat». Applied Physiology, Nutrition, and Metabolism, 38(3), 292-299. 
[4] BOYAS, S., REMAUD, A., BISSON, E. J., CADIEUX, S., MOREL, B. eta BILODEAU, M. 2011. «Impairment in postural control is greater when ankle plantarflexors and dorsiflexors are fatigued simultaneously than when fatigued separately». Gait and Posture, 34(2), 254-259.

[5] GIANDOLINI, M., VERNILLO, G., SAMOZINO, P., HORVAIS, N., EDWARDS, W. B., MORIN, J. eta MILLET, G. Y. 2016. «Fatigue associated with prolonged graded running». European Journal of Applied Physiology, 116(10), 1859-1873.

[6] MACLAREN, D. P., GIBSON, H., PARRY-BILLINGS, M. eta EDWARDS, R. H. 1989. «A review of metabolic and physiological factors in fatigue». Exercise and Sport Sciences Reviews, 17(1), 29-66.

[7] CAMERON, M. H. 2013. Agentes físicos en rehabilitación: De la investigación a la práctica. Elsevier, Espainia.

[8] GALLEGO IZQUIERDO, T. 2007. Bases teóricas y fundamentos de la fisioterapia. Médica Panamericana, Espainia.

[9] CABELlO, M. A. eta GALlUT, A. J. M. 2012. Procedimientos generales de fisioterapia + StudentConsult en español: Práctica basada en la evidencia. Elsevier, Espainia.

[10] ADAMCZYK, J. G., KRASOWSKA, I., BOGUSZEWSKI, D. eta REABURN, P. 2016. «The use of thermal imaging to assess the effectiveness of ice massage and cold-water immersion as methods for supporting post-exercise recovery». Journal of Thermal Biology, 60, 20-25.

[11] FUENTES, G. R. eta SANTOS, R. I. 2002. «Bases físicas de la hidroterapia». Fisioterapia, 24, 14-21.

[12] FERNÁNDEZ, M. P. eta CASTRO, B. N. 2002. Historia del agua como agente terapéutico». Fisioterapia, 24, 3-13.

[13] CORDERO, J. E. M. 2008. Agentes físicos terapéuticos. Ciencias Médicas, Espainia.

[14] BIEUZEN, F., BLEAKLEY, C. M., eta COSTELlO, J. T. 2013. Contrast water therapy and exercise induced muscle damage: a systematic review and meta-analysis. PLoS One, 8(4), e62356.

[15] BLEAKLEY, C. M. eta DAVISON, G. W. 2010. «What is the biochemical and physiological rationale for using cold-water immersion in sports recovery? A systematic review». British Journal of Sports Medicine, 44(3), 179187.

[16] JUNIOR, E. C. L., DE GODOI, V., MANCALOSSI, J. L., ROSSI, R. P., DE MARCHI, T., PARENTE, M., ... eta FRIGO, L. 2011. «Comparison between cold water immersion therapy (CWIT) and light emitting diode therapy (LEDT) in short-term skeletal muscle recovery after high-intensity exercise in athletes-preliminary results». Lasers in Medical Science, 26(4), 493-501.

[17] WILCOCK, I. M., CRONIN, J. B. eta HING, W. A. 2006. «Physiological response to water immersion». Sports Medicine, 36(9), 747-765. 
[18] MACHADO, A. F., FERREIRA, P. H., MICHELETTI, J. K., DE ALMEIDA, A. C., LEMES, Í R., VANDERLEI, F. M., ... eta PASTRE, C. M. 2016. «Can water temperature and immersion time influence the effect of cold water immersion on muscle soreness? A systematic review and metaanalysis». Sports Medicine, 46(4), 503-514.

[19] COSTEllo, J. T., CUlligAN, K., SElFE, J. eta DONNELly, A. E. 2012. «Muscle, skin and core temperature after $-110^{\circ} \mathrm{C}$ cold air and $8^{\circ} \mathrm{C}$ water treatment». PloS One, 7(11), e48190.

[20] HAUSSWIRTH, C., LOUIS, J., BIEUZEN, F., POURNOT, H., FOURNIER, J., FILLIARD, J. eta BRISSWALTER, J. 2011. «Effects of wholebody cryotherapy vs. far-infrared vs. passive modalities on recovery from exercise-induced muscle damage in highly-trained runners». PloS One, 6(12), e 27749.

[21] BROATCH, J. R., PETERSEN, A. eta BISHOP, D. J. 2014. «Postexercise cold-water immersion benefits are not greater than the placebo effect». Medicine and Science in Sports and Exercise, 46(11), 2139-2147.

[22] LEEDER, J., GISSANE, C., VAN SOMEREN, K., GREGSON, W. eta HOWATSON, G. 2012. "Cold water immersion and recovery from strenuous exercise: A meta-analysis». British Journal of Sports Medicine, 46(4), 233-240.

[23] POURNOT, H., BIEUZEN, F., DUFFIELD, R., LEPRETRE, P., COZZOLINO, C. eta HAUSSWIRTH, C. 2011. Short term effects of various water immersions on recovery from exhaustive intermittent exercise. European Journal of Applied Physiology, 111(7), 1287-1295.

[24] ROBERTS, L. A., RAASTAD, T., MARKWORTH, J. F., FIGUEIREDO, V. C., EGNER, I. M., SHIELD, A., ... eta PEAKE, J. M. 2015. «Post-exercise cold water immersion attenuates acute anabolic signalling and longterm adaptations in muscle to strength training». The Journal of Physiology, 593(18), 4285-4301.

[25] BROPHY-WILLIAMS, N., LANDERS, G. eta WALLMAN, K. 2011. «Effect of immediate and delayed cold water immersion after a high intensity exercise session on subsequent run performance». Journal of Sports Science and Medicine, 10(4), 665-670.

[26] STANLEY, J., BUCHHEIT, M. eta PEAKE, J. M. 2012. «The effect of post-exercise hydrotherapy on subsequent exercise performance and heart rate variability». European Journal of Applied Physiology, 112(3), 951-961.

[27] BAILEY, D., ERITH, S., GRIFFIN, P., DOWSON, A., BREWER, D., GANT, N. eta WILLIAMS, C. 2007. «Influence of cold-water immersion on indices of muscle damage following prolonged intermittent shuttle running». Journal of Sports Sciences, 25(11), 1163-1170.

[28] CRYSTAL, N. J., TOWNSON, D. H., COOK, S. B. eta LAROCHE, D. P. 2013. «Effect of cryotherapy on muscle recovery and inflammation following a bout of damaging exercise». European Journal of Applied Physiology, 113(10), 2577-2586. 
[29] ASCENSAO, A., LEITE, M., REBELO, A. N., MAGALHÄES, S. eta MAGALHÄES, J. 2011. «Effects of cold water immersion on the recovery of physical performance and muscle damage following a one-off soccer match». Journal of Sports Sciences, 29(3), 217-225.

[30] ELIAS, G. P., WYCKELSMA, V. L., VARLEY, M. C., MCKENNA, M. J. eta AUGHEY, R. J. 2013. «Effectiveness of water immersion on postmatch recovery in elite professional footballers». International Journal of Sports Physiology and Performance, 8(3), 243-253.

[31] ELIAS, G. P., VARLEY, M. C., WYCKELSMA, V. L., MCKENNA, M. J., MINAHAN, C. L. eta AUGHEY, R. J. 2012. «Effects of water immersion on posttraining recovery in australian footballers». International Journal of Sports Physiology and Performance, 7(4), 357-366.

[32] DELEXTRAT, A., CALlEJA-GONZÁlEZ, J., HIPPOCRATE, A. eta CLARKE, N. D. 2013. «Effects of sports massage and intermittent coldwater immersion on recovery from matches by basketball players». Journal of Sports Sciences, 31(1), 11-19.

[33] GOODALL, S. eta HOWATSON, G. 2008. «The effects of multiple cold water immersions on indices of muscle damage». Journal of Sports Science and Medicine, 7(2), 235-241.

[34] HOWATSON, G., GOODALL, S. eta VAN SOMEREN, K. 2009. «The influence of cold water immersions on adaptation following a single bout of damaging exercise». European Journal of Applied Physiology, 105(4), 615.

[35] JAKEMANM, J., MACRAE, R. eta ESTON, R. 2009. «A single 10-min bout of cold-water immersion therapy after strenuous plyometric exercise has no beneficial effect on recovery from the symptoms of exercise-induced muscle damage». Ergonomics, 52(4), 456-460.

[36] ESTON, R. eta PETERS, D. 1999. «Effects of cold water immersion on the symptoms of exercise-induced muscle damage». Journal of Sports Sciences, 17(3), 231-238.

[37] KULIGOWSKI, L. A., LEPHART, S. M., GIANNANTONIO, F. P. eta BLANC, R. O. 1998. «Effect of whirlpool therapy on the signs and symptoms of delayed-onset muscle soreness». Journal of Athletic Training, 33(3), 222-228.

[38] BASTOS, F., VANDERLEI, L., NAKAMURA, F., BERTOLLO, M., GODOY, M., HOSHI, R., eta PASTRE, C. 2012. «Effects of cold water immersion and active recovery on post-exercise heart rate variability». International Journal of Sports Medicine, 33(11), 873-879.

[39] PEIFFER, J. J., ABBISS, C. R., NOSAKA, K., PEAKE, J. M. eta LAURSEN, P. B. 2009. «Effect of cold water immersion after exercise in the heat on muscle function, body temperatures, and vessel diameter». Journal of Science and Medicine in Sport, 12(1), 91-96.

[40] MONTGOMERY, P. G., PYNE, D. B., HOPKINS, W. G., DORMAN, J. C., COOK, K. eta MINAHAN, C. L. 2008. «The effect of recovery strategies 
on physical performance and cumulative fatigue in competitive basketball». Journal of Sports Sciences, 26(11), 1135-1145.

[41] IHSAN, M., WATSON, G., LIPSKI, M. eta ABBISS, C. R. 2013. «Influence of postexercise cooling on muscle oxygenation and blood volume changes». Medicine and Science in Sports and Exercise, 45(5), 876-882.

[42] MORITANI, T., SHERMAN, W. M., SHIBATA, M., MATSUMOTO, T. eta SHINOHARA, M. 1992. "Oxygen availability and motor unit activity in humans». European Journal of Applied Physiology and Occupational Physiology, 64(6), 552-556.

[43] KNIGHT, K. L. eta LONDEREE, B. R. 1980. «Comparison of blood flow in the ankle of uninjured subjects during therapeutic applications of heat, cold, and exercise». Medicine and Science in Sports and Exercise, 12(1), 76-80.

[44] SIK PARK, K., KYU CHOI, J. eta SAENG PARK, Y. 1999. «Cardiovascular regulation during water immersion». Applied Human Science, 18(6), 233241.

[45] ŠRÁMEK, P., ŠIMEČKOVÁ, M., JANSKÝ, L., ŠAVLÍKOVÁ, J. eta VYBIRAL, S. 2000. «Human physiological responses to immersion into water of different temperatures». European Journal of Applied Physiology, 81(5), 436-442.

[46] TIKUISIS, P., JACOBS, I., MOROZ, D., VALLERAND, A. L. eta MARTINEAU, L. 2000. «Comparison of thermoregulatory responses between men and women immersed in cold water». Journal of Applied Physiology, 89(4), 1403-1411.

[47] SELLWOOD, K. L., BRUKNER, P., WILliAMS, D., NICOL, A. eta HINMAN, R. 2007. «Ice-water immersion and delayed-onset muscle soreness: A randomized controlled trial». British Journal of Sports Medicine, 41(6), 392397.

[48] ALGAFLY, A. A. eta GEORGE, K. P. 2007. «The effect of cryotherapy on nerve conduction velocity, pain threshold and pain tolerance». British Journal of Sports Medicine, 41(6), 365-9; discussion 369.

[49] REID, G., BABES, A. eta PLUTEANU, F. 2002. "A cold-and menthol-activated current in rat dorsal root ganglion neurones: Properties and role in cold transduction». The Journal of Physiology, 545(2), 595-614.

[50] HERRERA, E., SANDOVAL, M. C., CAMARGO, D. M. eta SALVINI, T. F. 2010. «Motor and sensory nerve conduction are affected differently by ice pack, ice massage, and cold water immersion». Physical Therapy, 90(4), 581-591.

[51] HALSON, S. L., QUOD, M. J., MARTIN, D. T., GARDNER, A. S., EBERT, T. R. eta LAURSEN, P. B. 2008. «Physiological responses to cold water immersion following cycling in the heat». International Journal of Sports Physiology and Performance, 3(3), 331-346.

[52] LOW, J., REED, A. eta POPE, G. D. 1994. Physical principles explained. Physiotherapy, 80(12), 869.

[53] MAWHINNEY, C., JONES, H., JOO, C. H., LOW, D. A., GREEN, D. J. eta GREGSON, W. 2013. «Influence of cold-water immersion on limb and cuta- 
neous blood flow after exercise». Medicine and Science in Sports and Exercise, 45(12), 2277-2285.

[54] HOHENAUER, E., TAEYMANS, J., BAEYENS, J., CLARYS, P. eta CLIJSEN, R. 2015. "The effect of post-exercise cryotherapy on recovery characteristics: A systematic review and meta-analysis». PLoS One, 10(9), e0139028.

[55] ROWSELl, G. J., COUTTS, A. J., REABURN, P. eta HILL-HAAS, S. 2011. Effect of post-match cold-water immersion on subsequent match running performance in junior soccer players during tournament play. Journal of Sports Sciences, 29(1), 1-6.

[56] WHITE, G. E. eta WELLS, G. D. 2013. «Cold-water immersion and other forms of cryotherapy: Physiological changes potentially affecting recovery from high-intensity exercise». Extreme Physiology and Medicine, 2(1), 26.

[57] FROHLICH, M., FAUDE, O., KLEIN, M., PIETER, A., EMRICH, E. eta MEYER, T. 2014. «Strength training adaptations after cold-water immersion». Journal of Strength and Conditioning Research, 28(9), 2628-2633.

[58] ROBERTS, L. A., NOSAKA, K., COOMBES, J. S. eta PEAKE, J. M. 2014. «Cold water immersion enhances recovery of submaximal muscle function after resistance exercise». American Journal of Physiology. Regulatory, Integrative and Comparative Physiology, 307(8), R998-R1008.

[59] WILSON, L. J., COCKBURN, E., PAICE, K., SINCLAIR, S., FAKI, T., HILLS, F. A., eta DIMITRIOU, L. 2018. «Recovery following a marathon: A comparison of cold water immersion, whole body cryotherapy and a placebo control». European Journal of Applied Physiology, 118(1), 153-163.

[60] RAMOS, S. P., BARA-FILHO, M. G., FREITAS, D. G., COIMBRA, D. R., CECCHINI, R., GUARNIER, F. A., ... eta NAKAMURA, F. Y. 2019. «Effect of cold water immersion performed on successive days on physical performance, muscle damage, and inflammatory, hormonal, and oxidative stress markers in volleyball players». Journal of Strength and Conditioning Research, 33(2), 502-513.

[61] PEAKE, J., ROBERTS, L. A., FIGUEIREDO, V. C., EGNER, I., KROG, S., AAS, S. N., eta CAMERON-SMITH, D. 2017. «The effects of cold water immersion and active recovery on inflammation and cell stress responses in human skeletal muscle after resistance exercise». The Journal of Physiology, 595(3), 695-711.

[62] STEPHENS, J. M., HALSON, S. L., MILLER, J., SLATER, G. J., CHAPMAN, D. W. eta ASKEW, C. D. 2018. «Effect of body composition on physiological responses to cold water immersion and the recovery of exercise performance». International Journal of Sports Physiology and Performance, 13(3), 382-389. 